\title{
V \\ BOOK REVIEW
}

\section{THE TREATMENT OF SYPHILIS*}

THE investigation undertaken by Colonel Harrison into the results of treatment for early syphilis at St. Thomas's Hospital over the period from January, I920, to the end of March, I926, is one of the very highest value. As presented in this report, it is a work which must be read with interest and studied with care by every syphilologist. The labour involved in collecting, sifting, classifying, and critically analysing the records must have been enormous; but the result shows how well worth while it has been. Although all the conclusions arrived at by Colonel Harrison may not secure universal acceptance, nevertheless the investigation he has carried out is a notable, important, and eminently practical contribution to modern syphilology. It must surely have the effect of stimulating others in charge of clinics to tabulate and examine their case records in a similar manner.

In the publication under review there is set out in a very detailed fashion a rich array of facts relative to the modern treatment of early syphilis and the results therefrom. The conclusions to be arrived at from a consideration of these will, naturally, vary according to the mind of the interpreter. And each interpretation deserves consideration. The main point at issue is to decide as to what constitutes adequate treatment for early syphilis.

As Colonel Harrison points out, there is among syphilologists a great diversity of opinion as to the treatment of syphilis in respect of its amount, duration, agents used, and the manner in which these should be exhibited. " Clearly," he says, " the large body of workers at each extreme cannot be right. Either the patients of many are being seriously undertreated, or those of many others are being grossly overtreated." When patients are being

* “The Treatment of Syphilis" : A survey of records from St. Thomas's Hospital, by L. W. Harrison, D.S.O., M.B., F.R.C.P.E., Brevet-Colonel, R.A.M.C. and K.H.P. (Ret.) ; Director of Venereal Diseases Department, St. Thomas's Hospital, London. Medical Research Council Special Report, Series No. I32. London, H.M. Stationery Office, 1929. Price 2s. net. 


\section{BRITISH JOURNAL OF VENEREAL DISEASES}

undertreated their future is jeopardised and they may be the means of spreading, unwittingly, their uncured disease to others. On the other hand, where overtreatment takes place, not only is much labour, time, money and material being wasted, but the body of the patient may be actually damaged by the over-use of the agents employed. From every point of view, thenthat of the patient, the syphilologist, the State, and the health of future generations-it is of vital importance that there be some settlement of this matter of adequate treatment. One would therefore heartily endorse Colonel Harrison's hope that all workers will take stock of their results and support their views with definite evidence. It is also to be recommended that directors of clinics who do carry out such a stocktaking will proceed upon the excellent lines laid down in this report. By so doing the necessary comparisons will be facilitated.

The principle upon which treatment is carried out at St. Thomas's Hospital is that known as " concurrent." This means that an arsenobenzene compound (Ab.C)usually of the " 9I4" type-is administered concurrently with either bismuth $(\mathrm{Bi})$ or mercury $(\mathrm{Hg})$. The standard adopted for a "full course " was that it must consist of not less than $5 \mathrm{gm}$. of $\mathrm{Ab}$.C along with $5 \mathrm{gr}$. of $\mathrm{Hg}$ or $2 \mathrm{gm}$. of $\mathrm{Bi}$ over a period of not more than sixteen weeks. Before a case was considered to have been treated with two regular courses, the patient must have received an initial course as stated above, have commenced the second course within twelve weeks of the end of the first one, and have completed it not more than sixteen weeks later.

The analysis of cases shows that in primary seronegative syphilis a satisfactory percentage of cures cannot be expected from less than two regular courses. In other words, it takes Io gm. of Ab.C plus $4 \mathrm{gm}$. of $\mathrm{Bi}$ administered during forty-four weeks to bring about cure. In sero-positive primary and in early secondary cases, three such courses- $5 \mathrm{gm}$. of Ab.C along with $6 \mathrm{gm}$. of $\mathrm{Bi}$ in fifty-six weeks - are insufficient.

The rival school of treatment adopts the principle of administering Ab.C and $\mathrm{Bi}$ in alternating " bursts." For example, in sero-positive primary syphilis a representative alternating course would be eight weekly injections of $\mathrm{Ab} . \mathrm{C}$ succeeded by sixteen twice-weekly injections of 
$\mathrm{Bi}$, each being repeated for a further sixteen weeks without any rest interval-the total time occupied being thirty-two weeks. The adherents of the alternating method claim that under their régime, in which $9 \mathrm{gm}$. of Ab.C and $6.4 \mathrm{gm}$. of $\mathrm{Bi}$ are administered, a completely satisfactory percentage of cures is obtained; and, furthermore, that it not only shows a saving in time of some twelve weeks, but causes considerably less damage to the patient's tissues than does the concurrent method.

The controversy as to which method is the better, cannot be finally settled until a clinic working upon the alternating principle with a large number of cases analyses and publishes its results, so that they may be compared with those obtained under the other system.

The criteria of cure adopted in Colonel Harrison's investigations were as stringent as is compatible with treatment centre work, except that perhaps the provocative Wassermann procedure might be taken into routine use. It is the reviewer's experience that the provocative injection of Ab.C intravenously, preceeded by four weeks saturation with iodides, and the taking of a Wassermann test every twenty-four hours for seven days after the injection, uncovers a good deal of uncured syphilis which would otherwise be missed.

It is at first sight rather remarkable and unexpected to find that $\mathrm{Bi}$ is shown in Colonel Harrison's investigation to have no greater a therapeutic effect than has $\mathrm{Hg}$. This is in direct opposition to Kolmer's findings.* He investigated the comparative treponemicidal powers of various drugs in experimental rabbit syphilis. The chemotherapeutic indices of these agents indicate in a general way their respective activities, and it was found that the arsenobenzene compounds were highest therapeutically, followed by the pentavalent arsenicals, then by $\mathrm{Bi}$ and lastly by $\mathrm{Hg}$. "If," as Kolmer says, " the chemotherapeutic indices may be used for expressing comparative spirochæticidal effects, these various compounds may be listed as follows :

Trivalent organic arsenicals (Ab.C) . Io to I8

Pentavalent organic arsenicals . . 2 , 6

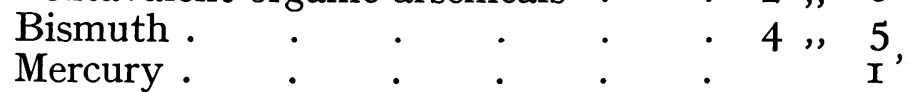

* Kolmer. "Chemotherapy and Trextment of Syphilis," p. 907. Lo.1don. Saunders, 1926. 


\section{BRITISH JOURNAL OF VENEREAL DISEASES}

This scaling of therapeutic value is fairly generally accepted, and it is fully corroborated by those who use the agents in alternating series. Hence it might be legitimately suggested that Colonel Harrison's unexpected experience is to be attributed to the fact that in his cases the $\mathrm{Bi}$ or the $\mathrm{Hg}$ was given simultaneously with the Ab.C. It might also be suggested that the effect of concurrent administration is to reduce the intrinsic therapeutic power of $\mathrm{Bi}$ to that of $\mathrm{Hg}$. $\mathrm{Ab} . \mathrm{C}$ and $\mathrm{Bi}$ act indirectly by stimulating the tissues to produce a toxalbumin lethal to the infecting parasite. $\mathrm{Hg}$ has a slight direct action upon the organism, and may, in addition, stimulate tissue immunity. Those who belong to the alternating school hold that the therapeutic value of $\mathrm{Ab} . \mathrm{C}$ and $\mathrm{Bi}$ given together is not equal to the sum of their values when given separately. The main reason they advance for this is that by concurrent administration the tissues tend to become exhausted and are unable to produce the curative substances in satisfactory quantity and quality.

Another point that must be taken into consideration with respect to this matter is the fact that the Treponema pallidum does acquire a resistance to Ab.C, to $\mathrm{Hg}$, and probably to $\mathrm{Bi}$ as well. Akatsu and Noguchi * increased the in vitro resistance of the parasite of syphilis from three to five and a half times its natural resistance to Ab.C. Klauder $\uparrow$ showed that a similar resistance may be acquired in vivo. He found that the minimal curative dose of Ab.C for rabbits with testis inoculations was o.oIo gm. per kilo by intravenous injection. By treating rabbits with sub-curative doses, and transplanting to fresh animals, he found that the resistance was, after several transfers, so raised that the minimal curative dose was more than $0.016 \mathrm{gm}$. per kilo. Those who favour the alternating method claim that by it drug resistance is not allowed to develop, and that by concurrent administration such resistance is encouraged to both $\mathrm{Ab} . \mathrm{C}$ and $\mathrm{Bi}$ at the same time.

It is important to keep these things in mind when considering the findings in Colonel Harrison's report that " the adjuvant effect of the bismuth compound employed was not greater than that of mercury." $\mathrm{He}$

* Akatsu and Noguchi. Journ. Exp. Med., XXV., 349, I9I 7.

$\dagger$ Klauder, quoted by Kolmer. "Chemotherapy and Treatment of Syphilis," p. 327,1926 . 


\section{BOOK REVIEW}

frankly admits, however, on p. II, that " a straight comparison of $\mathrm{Hg}$ with $\mathrm{Bi}$ is not possible in the St. Thomas's Hospital results because it has not been considered justifiable there to trust the fortunes of early cases of syphilis to either $\mathrm{Hg}$ or Bi used alone." Such a straight comparison is only possible where the alternating system is in operation; and in such clinics the fact emerges quite clearly that the therapeutic potency of $\mathrm{Bi}$ is much greater than that of $\mathrm{Hg}$, and is in accordance with the list given by Kolmer and quoted above. It is for this reason that the reviewer so strongly holds that where there exists no contra-indication to $\mathrm{Ab} . \mathrm{C}$ or $\mathrm{Bi}$, then $\mathrm{Hg}$ is obsolete in the treatment of syphilis.

There is much evidence to support the principle of alternating treatment in this report. For example, on p. I4, it is stated that " another course . . . is now being tried in which the total dosage per course is $6.75 \mathrm{gm}$. Ab.C with $4 \mathrm{gm}$. $\mathrm{Bi}$, but the Ab.C is administered in groups of three, and later two, injections at weekly intervals, each group being followed by a rest from Ab.C lasting a month, so that the last injection of ' $9 \mathrm{I} 4$ ' in the course is given r2o days after the first. The total of $4 \mathrm{gm}$. Bi is administered in ten injections at weekly intervals from the first, so as to preserve throughout the continuity of attack." This is surely a big step in the direction of alternation; it approaches very closely to it. It was indeed apparently suggested by the pre-war experience of alternation at the Military Hospital in Rochester Row. Colonel Harrison says with regard to this experience: "This course consisted of $0.6 \mathrm{gm}$. ' 606 ' ; five weekly injections of $\mathrm{Hg} ; 0.6 \mathrm{gm}$. ' 606 '; five weekly injections of $\mathrm{Hg}$; and, lastly, $0.6 \mathrm{gm}$. ' 606 .' It caused neither jaundice nor dermatitis, and it seemed possible that it might have owed some of its success to the fact that the tissues were not bombarded week after week with Ab.C, but had an opportunity of recovering." Exactly!

The effect of the new course has been serologically not inferior to the old one, and "it has been attended by a smaller incidence of skin disturbances." Skin, renal and hepatic damage are practically unknown where the alternating method is adopted. Colonel Harrison remarks that " to secure improvements on the present results, greater attention must be paid to the patient's 


\section{BRITISH JOURNAL OF VENEREAL DISEASES}

tissues." The reviewer is here in complete agreement; but he would venture to submit again that the best way, not only of protecting the patient's tissues, but of securing their co-operation, is by the alternating method of treatment ; and, furthermore, that this is borne out to a very great extent by the results of Colonel Harrison's own investigation.

One very interesting and practical point is brought out in the Report and it is that in respect of the therapeutic value of various brands of arsenobenzene compounds with the same chemical constitution, no important difference was noted. The preparations used were Novarsenobillon, Neokharsivan, Neosalvarsan, Novarsan and Stabilarsan, and the route of administration was intravenous. In the reviewer's clinic the last-named is the compound used as a routine; and it has been adopted as such on account of two main factors: (I) it is productive of fewer toxic reactions, immediate or delayed, and this is probably due to the fact that the agent is already dissolved in an isotonic glucose solution, hence there is no risk of contamination with faulty distilled water, there are no undissolved particles, and the glucose constitutes a barrier against toxicity and against hepatic damage ; (2) being already in solution, there is a great saving of time in preparing the injection over those preparations which are in powder form and require to be dissolved.

The investigation shows in a striking manner the fact that as the disease advances in age the amount of treatment required increases and the prognosis becomes worse. The lesson is obvious.

Colonel Harrison's experience of sero-negative primary cases showed that, while all those who had not been negative at the end of the first course had responded well to further treatment, two which had been completely negative had a further history which was not satisfactory. There is much evidence to show that the securing of a negative serology abnormally early in treatment indicates a lack of resistance to the disease on the part of the patient. It is occasionally found that florid syphilis in the secondary stage exists in the presence of a negative blood Wassermann, and that when such a condition is present there is little or no response to antisyphilitic treatment. 


\section{BOOK REVIEW}

The Lancet of July 7 th, I928, quotes a case reported in the Dermatologische Wochenschrift, p. 727, June 2nd, I928, with reference to syphilis refractory to treatment. A man, aged forty-two, received the usual arsenical and bismuth course for a profuse secondary eruption. Fourteen days later condylomatous lesions developed on the tongue and round the anus, although the Wassermann reaction was negative. Renewed antiluetic treatment brought about the disappearance of the lesions and a positive W.R. The first mercurial injection of the third course was followed by an urticarial syphilitic eruption, and the W.R. became negative again. This eruption was uninfluenced by intensive treatment with neosalvarsan, bismuth and iodides, but the W.R. remained negative. An intra-cutaneous injection was given of syphilitic vaccine from rabbit chancres ("luotestin" $0 \cdot 2$ c.c.). Pronounced local and focal reaction in the lesions followed the first injection, and after the second the W.R. became positive. The third injection resulted in the involution of the eruption. Four more doses of luotestin were given, and the treatment was then purposely stopped. Ten days later there was a gyrate macular rash on the trunk and syphilitic papules on the right tonsil; and now the W.R. was, as it should be, positive. Another injection of luotestin and a small dose (0.15 gm.) of neosalvarsan promptly cleared up both these manifestations, which had not recurred at the time of reporting the case. It will be noted that an abnormally reacting organism, indicated by the urticarial eruption, negative W.R., and refractiveness to salvarsan, was converted into a normally reacting mechanism as evidenced by the macular eruption, positive W.R., and receptivity to salvarsan. Rosner, who reports the case, takes the view that the negative W.R. during the eruptive stage is a sign of defective natural protection. It seems probable that the injections of luotestin to some extent stimulated production of antibodies. This would explain the appearance of local and focal reaction in the rash itself, but does not quite account for the paradoxical gyrate eruption with tonsillar lesions that followed ten days after the seventh injection of luotestin. Rosner suggests the term "contra-reaction," and raises the question of an altered response of the bloodvessels in the lesions, leading to their paradoxical contraction, with dilatation of vessels in the vicinity. There 


\section{BRITISH JOURNAL OF VENEREAL DISEASES}

is no doubt that the administration of luotestin and similar protein bodies, which are not necessarily specific, have a practical bearing upon the treatment of refractory syphilis. Colonel Harrison remarks, on p. 2I : "The more or less unsatisfactory after-histories of a number of those [sero-positive primary cases] which were negative at the end of the first course and received regular treatment after this, shows again that the attainment of a negative reaction by the first course is not a guarantee of its maintenance even under regular treatment." Experience shows that clinical recurrences of a secondary type are four times more frequent in cases showing a prematurely negative Wassermann than in the average patient.

The adherents of the alternating method can only prove their case by showing a much lower serological relapse incidence after the completion of their regular course than is evidenced in Colonel Harrison's series of cases. On p. 29 there is the statement that " the explanation of relapses under continued treatment does not seem to lie altogether in irregularity of this treatment, and it may be that the tissues change so that they lose their original power of making of the injected remedies those derivatives which bring about the destruction of the syphilitic virus. . . . It may . . . be possible . . . that the plan of giving arsenobenzene injections week after week for eight or ten weeks defeats its object by damaging the tissues unduly." One would be inclined to agree if the words " simultaneously with bismuth " were inserted after " arsenobenzene injections." Tissue damage or tissue exhaustion will occur if any single agent is used too strongly or over too long a time; and it is surely not unreasonable to suppose that when two such agents are used simultaneously, the liability to such damage and exhaustion will be greater.

The matter of recurrent chancre, which accounted for a goodly proportion of relapses (seven out of twenty in sero-negative primary cases), is one of great interest and importance. Sir Jonathan Hutchinson was the first to mention, in I866, in the London Hospital Reports, the tendency to recurrence of induration in chancres. Two years later Fournier, in Les Archives Générales de Médecine, described the same condition. Under the Hutchinsonian mercurial regimen, induration began to melt away within a few weeks; but stoppage of treatment resulted 
in the sore again assuming hardness, frequently as well marked as at first. In the recurrent chancre of Hutchinson the induration is almost invariably exactly in the site of a former chancre. As a rule, no abrasion or ulcer precedes the hardness. There is no satellite adenopathy, and such recurrences are not followed by general cutaneous eruptions or sore throat. They appear to be quite isolated phenomena. Hutchinson stated that these chancres are never contagious, and he was of the opinion that " they illustrate the general law of gummata in being dependent on elements left behind by the original disease." Hutchinson puts the main differential point thus: "While the one begins by an ulcer which indurates, the other [recurrent chancre] begins as an induration which ulcerates."

There will be general agreement with Colonel Harrison's view that "early interference by treatment prevents the development of a local immunity, so that surviving $S p$. pallida provoke eventually a local renewal of tissue activity, which would not occur if the original chancre had been allowed to progress. ... . It seems possible that in human syphilis a . . . process of local immunisation occurs at every site of reaction between virus and tissues." It would seem that inadequate treatment of early syphilis rapidly induces a condition of late syphilis ; and that this is due not so much to a change upon the part of the organism, but to a change in the tissuesallergy. Where treatment is inadequate the stage of anaphylaxis is hastened, and such treatment given early in the disease tends to produce local relapses. There is much to support the view that modern agents such as arsenobenzene and bismuth have changed the course of syphilis, and that lesions of the so-called tertiary type may appear much earlier than when the disease is allowed to run its normal gait, during which a natural defensive mechanism is developed. The question of trauma may also have some bearing upon the recurrent chancre, it being well recognised that injury of the cutaneous tissues predisposes to the deposition of parasites in such areas. Secondary rashes, for example, are apt to be most marked in areas pressed upon by garments-the braces and belt area in men, and the corset area in women. Treponemata can be demonstrated in sections of skin where a papular syphilide has involuted twelve months or more previously. 
In considering the recurrent chancre one is driven inevitably to think of the question of reinfection. There are certain criteria, as pointed out by Stokes, which must be fulfilled before one can accept the case as being one of reinfection. There must be no doubt as to the previous syphilis, and the new chancre must conform to the following requirements : (a) the incubation period must be from ten to thirty days; $(b)$ the clinical appearance must be definite; $(c)$ the sore must be remote from the site of the original chancre; $(d)$ it must not be in the immediate lymphatic drainage of the old chancre; (e) there must be no signs of revival of the old chancre; $(f)$ the Treponema pallidum must be present in the new lesion; $(g)$ a new satellite adenopathy must develop. If untreated, the Wassermann must become positive and a secondary rash should appear in from twenty days onwards from the appearance of the new chancre. A great many of the cases reported as new infections fall very far short of complying with the above requirements.

One would support most strongly Colonel Harrison's plea for the local treatment of all chancres-not with the idea that such measures can modify the virulence or prevent the generalisation of the disease, but because of the danger of living parasites becoming entrenched within the initial sclerosis. Hectine, $0.2 \mathrm{gm}$., injected into the chancre is effective; and wherever possible a circumcision which will remove the chancre should be done.

The report devotes a special section (p. 40) to relapses with clinical signs of disease of the central nervous system. In several other places Colonel Harrison refers to this matter; for example on p. 45 he concludes that " the absence of any relapse in this series with clinical signs of neuro-syphilis is contrasted with the experience of another clinic in which neuro-recurrences were frequent, and it is suggested that a possible explanation of the difference may lie in the arrangement of the treatment, cases treated with arsenobenzene and mercury or bismuth simultaneously suffering less from neuro-recurrence than those treated with arsenobenzene alone or with a course of this remedy followed by one of $\mathrm{Hg}$ or Bi."

One is of the opinion that this question of the simultaneous or alternating principle of treatment is the 
most important practical point in modern syphilology. A statement such as that quoted above, emanating from so high an authority as Colonel Harrison, is one the repercussion of which must be felt in every treatment centre throughout the world. The reviewer thinks that there is another explanation to that suggested by Colonel Harrison; and he is, moreover, of the opinion that the incidence of neuro-recurrence in the clinic referred tothat of the Johns Hopkins Hospital in Baltimore-and the lack of such recurrences at St. Thomas's Hospital in London, is not a valid argument that the concurrent method is better than the alternating.

Colonel Harrison's statement is based first of all upon the fact that of all the cases of early syphilis treated at St. Thomas's Hospital from I920 till I928, there has only. been one who has returned with any clinical evidence of central nervous system involvement. That patient had only received two injections of $0.45 \mathrm{gm}$. of " $9 \mathrm{I} 4$ " and one of $\mathrm{Bi}$. He returned some months later with paraparesis. This experience is contrasted with that of Moore and Kemp, which is reported in the Johns Hopkins Hospital Bulletin for July, I926. (There is a misprint in Colonel Harrison's report, where the date is given as 1924.) They reviewed the records of 402 patients, and among these there were fifty-nine neuro-recurrencesacute syphilitic meningitis, cranial nerve palsies, precocious vascular neuro-syphilis, etc.

Everyone is agreed that a certain minimum amount of treatment is required to cure syphilis, and that therefore any amount less than that will fail to cure. Failure to cure may be evidenced in several ways; by recurrent chancre, by Wassermann relapse, by neuro-recurrence, by visceral damage, such as aortic aneurism, and so on. Now, some of these conditions are more clamant and dramatic than others; some are more apt to occur at an early datebut there is none more clamant, more dramatic, or earlier in appearing, than a neuro-recurrence. The condition attracts the attention of the patient, and he is driven to seek advice about it. The other conditions may be rather late in developing. If the patient has not had a blood test done his uncuredness may remain undiscovered for years until a well-marked aortic incompetence is in full blast. The point here is that a neuro-recurrence shows itself above the clinical horizon at an earlier time 


\section{BRITISH JOURNAL OF VENEREAL DISEASES}

and in a more striking manner than any other form of recurrence. Few such recurrences are missed. Few of the other types are recognised in anything like the same period. Again, it may be mentioned incidentally that in the writer's clinic, where alternating treatment is carried out, the incidence of neuro-recurrence is precisely that at St. Thomas's: a negative quantity.

Furthermore it may be legitimately argued that there is a good deal of advantage in the uncured patient coming again under observation and treatment at an early date, and that the last state of such a man suffering from a neuro-recurrence is infinitely better than the one who feels well for years and whose real condition is only discovered by a chance serological test or the development of a definite visceral lesion.

Antisyphilitic treatment of any kind may be regarded as an evil necessary to mitigate a greater one-syphilis ; and the choice between concurrence and alternation would resolve itself into selecting the one likely to produce the lesser degree of damage. Apart from this aspect, it is suggested that an early neuro-recurrence is much less grave than a late visceral involvement or a condition of Wassermann fastness. An inadequate amount of treatment upon either the alternating or the concurrent system will result in relapses of various kinds; but the value of either system is not to be assessed upon what happens to defaulting patients, but what happens to those who carry through their treatment according to the respective schedules.

Colonel Harrison uses the investigation of Moore and Kemp as a means of discrediting the alternating method which they adopt, and he does so by pointing to the 59 of their cases who developed neuro-recurrences out of 402 cases analysed. Now, Moore and Kemp divide their cases into four groups, according to the amount of treatment received. Group I. consisted of cases who received from I to 8 injections of $\mathrm{Ab}$. C with either no $\mathrm{Hg}$ at all or for less than one month; Group II. received from 6 to I2 injections of $\mathrm{Ab}$.C with $\mathrm{Hg}$ being used at least two months in the interim between the Ab.C courses; Group III. received from 13 to 20 injections with interim $\mathrm{Hg}$; and Group IV. were those who received from 2I to 40 injections of $\mathrm{Ab} . \mathrm{C}$ with interim $\mathrm{Hg}$. Into this Group IV. fall all patients who have completed Moore and Kemp's ideal 


\section{BOOK REVIEW}

course of treatment, which was outlined in Moore and Keidel's paper (Johns Hopkins Hospital Bulletin, XXXIX., I926). There were $7 I$ patients who completed their treatment according to this course, and among these there was no case of neuro-recurrence. The authors say: "If one groups together as serious recurrences those which greatly impair efficiency or endanger life (neuro-recurrences, tertiary syphilis and neuro-syphilis), the incidence of these falls from 44 per cent. after Group I. treatment, to 37 per cent. after Group II., to 24 per cent. after Group III., and to only 3 per cent. after Group IV. For all practical purposes, therefore, a satisfactory result (cure or arrest) may be obtained in 90 to 95 per cent. of all patients with early syphilis treated for a sufficiently long period of time." Be it noted here that Moore and Kemp used $\mathrm{Hg}$ in place of $\mathrm{Bi}$, and it is claimed by those who use the latter instead of $\mathrm{Hg}$ in the alternating scheme that Ioo per cent. results are obtainable.

In Moore and Kemp's series of neuro-recurrences the striking feature of the treatment received by the cases was its utter inadequacy. All the cases in the neurorecurrence group " occurred within the first year, and in 97 per cent. within the first six months. The average lapse was only $2 \cdot 7$ months. . . . That precocious neurosyphilis can develop under these conditions is one of the strongest arguments for the continuous treatment of early syphilis. After once beginning treatment it is absolutely unsafe to permit a patient with primary or secondary syphilis to pass a single day without the influence of a treponemicidal drug." If $\mathrm{Ab} . \mathrm{C}$ and $\mathrm{Hg}$ or $\mathrm{Bi}$ are given concurrently it is clear that after a short time there must be a temporary suspension of treatment. A restperiod must be given, because there is a limit of bodily toleration for these agents. Moore and Keidel point out that "it is of paramount importance to consider the reaction of the patient. The course of events in an untreated infection with gradually developing insusceptibility to reinfection, and culminating in the spontaneous disappearance of the secondary outbreak, the destruction of large numbers of treponemes, and latency, indicates a considerable degree of resistance upon the part of the patient. If treatment is begun in the primary or secondary stage of the disease, and the sequence of general tissue reaction, the appearance of lesions and their spon- 


\section{BRITISH JOURNAL OF VENEREAL DISEASES}

taneous resolution is sharply interrupted, the development of the patient's own resistance against the treponeme is wholly or partially prevented. The patient thus enters on the first rest-period without adequate resistance against the living treponemes remaining in his tissues, and must elaborate his immune reactions afresh. Depending upon the location of the surviving organisms, and the length of time between treatment courses, he may repeat the process of general dissemination and tissue reaction, culminating in delayed or recurrent secondary syphilis; or he may develop that bugbear of early syphilis, a neuro-recurrence."

The criteria of cure adopted by the American workers was of a much more stringent character than that obtaining at St. Thomas's Hospital, or indeed is advisable or perhaps possible, in any venereal diseases treatment centre in this country. Moore and Kemp require a full year of probation during which no treatment is given. The patient develops no syphilitic lesions, and the bloodWassermann test, frequently repeated, is consistently negative. "At the end of the year a complete physical and neurologic examination must show no evidence of progress in the disease, especially in the nervous system or cardiovascular apparatus. The absence of neuraxial involvement must be demonstrated, not only by freedom from neurologic signs, but also by a negative examination of the cerebro-spinal fluid. A negative fluoroscopic and roentgenologic examination of the cardiovascular stripe must confirm thenegative physicalfindings in thisdomain."

One is inclined to suggest that the incidence of neurorecurrence in the American series cannot be attributed to the alternating method, because that method in this country does not, even with inadequate treatment, lead to neuro-recurrence. The American results in this respect, where the treatment has not been carried out according to schedule, may be partly due to racial differences, to the use of "606" instead of " 914 ," and to the giving of $\mathrm{Hg}$ instead of $\mathrm{Bi}$.

In Colonel Harrison's report there is a very interesting analysis of the occupations of patients on first reporting at the clinic. A total of 3,598 cases were analysed, and it is shown that roughly ro per cent. of patients were engaged in road transport work. In the reviewer's clinic the high percentage of patients who are transport workers 


\section{BOOK REVIEW}

is also very striking. One feels that this is an important fact, and may bear a very close relationship to the matter of road accidents. The danger from a late syphilitic driving a heavy lorry or a 'bus is obvious.

The table dealing with the ages and marital condition of patients is also important. "The ratios seem to show that a married man of twenty to twenty-four is much more likely to contract syphilis than is one of greater age." There are here vital sociological implications to which serious attention must be paid. The incidence of the disease is apparently greatest in the age-group most intimately concerned with the future of the race. Colonel Harrison's analysis shows very clearly the need for propaganda and for the teaching of social hygiene to adolescents so that the potential parents of the next generation may not pass on a legacy of syphilis to their children. And it may not be irrelevant here to express the hope that local authorities responsible for venereal diseases schemes will realise that these responsibilities do not begin and end with the establishment and maintenance of treatment centres. The centres are merely attempting to clear up the mess. A really serious and persistent effort must be made to " turn off the tap." A treatment centre working in the absence of a well-conceived and continuous propaganda campaign is a financially unsound proposition. Each centre should be in close liaison with a local branch of the British Social Hygiene Council; and it is an essential duty of the local authority concerned to render to that organisation monetary support upon the scale recommended- - I per I,ooo population.

Under the new Local Government Act there takes place a readjustment of the various public health activities, and there may be a tendency in some areas to curtail anti-venereal effort in favour of other branches which are more popular and attaching to which there is no taboo. Hitherto the payment of 75 per cent. of the cost of the Venereal Diseases Scheme by the Ministry of Health was not only an encouragement to apathetic local authorities to provide free treatment, but it gave the Ministry a great deal of control in the direction of securing efficiency. Such control is essential, and it is devoutly to be hoped that it will not be lost under the new conditions. The recently issued Ministry of Health Circular No. I,072 lays down certain general requirements as to 


\section{BRITISH JOURNAL OF VENEREAL DISEASES}

the qualifications and experience which must be possessed by medical officers. After March 3Ist. local authorities do not require to obtain the approval of the Ministry with respect to appointments made, provided that the regulations embodied in the Circular are adhered to. In future, before a venereal diseases officer can be appointed, he must be in possession of a certificate given by the venereal diseases officer of a treatment centre at which not less than 500 patients attended for the first time during the twelve months preceding the issue of the certificate, testifying that he has attended at the treatment centre for not less than threemonths, and has received during that period not less than I30 hours' instruction in the modern methods of diagnosis and treatment of venereal diseases.

At this opening of a new era the writer would like to express here an acknowledgment of the great debt that public health in general, and the branch of venereal diseases in particular, owes to Colonel Harrison. Indefatigable industry, wide vision, prudence, and sane enthusiasm have characterised his work throughout. Vast clinical experience, coupled with profound pathological knowledge, have, in his personality, been the basis upon which the Venereal Diseases Scheme has been built and maintained. It is the general hope that in the new organisation of the health activities of this country his firm hand will continue to hold the wheel and guide the destinies of the V.D. service.

In this review it has been considered necessary to criticise at some length the concurrent method of treatment and to point out in what respects it is-in the reviewer's opinion, at least-unsound. In doing so, however, one does not seek to minimise in the slightest degree the high esteem in which the world rightly holds Colonel Harrison's work. There has been no British venerologist whose labours have had a deeper influence upon the subject both at home and abroad than he. That influence has been an energising one-pursuing knowledge without fear and without reproach. And if upon certain aspects of the report the reviewer has cried "Audi alteram partem," it is because he would endeavour, however inadequately, to emulate Colonel Harrison's courage and courtesy in matters of scientific controversy.

E. T. B. 